\title{
Fatty acid and fat soluble vitamins composition of raw and cooked Black Sea horse mackerel
}

\author{
Albena MERDZHANOVA*, Mona STANCHEVA, Diana A. DOBREVA and Lyubomir MAKEDONSKI \\ Department of Chemistry, Medical University of Varna, 55 Marin Drinov Str., 9002 Varna, Bulgaria
}

\begin{abstract}
The fat soluble vitamins, as well as $\mathrm{n} 3$ and $\mathrm{n} 6$ fatty acids (FA) are essential compounds of fish lipids and exclusively provided by the diet. Fish is sometimes eaten raw, but it is usually thermal processed before consumption. Temperature processing of fish tissue enhances its taste, inactivates pathogenic microorganisms and increases its shelf life. The fat soluble vitamins (vitamins $\mathrm{A}, \mathrm{D}_{3}$ and $\mathrm{E}$ ) and fatty acids are considered to be susceptible to oxidation during heating (cooking) process. The aim of the present study was to evaluate the effect of steaming $\left(10 \mathrm{~min}\right.$ at $\left.90^{\circ} \mathrm{C}\right)$ and frying $(5 \mathrm{~min}$ on the each side with sunflower oil) on fat soluble vitamins and fatty acids composition in Horse mackerel (Trahurus mediterraneus) fish fillets. Vitamins $\mathrm{A}, \mathrm{D}_{3}$ and $\mathrm{E}$ were analyzed simultaneously using RP-HPLC. The fatty acid composition was analyzed by GC-MS. The amounts of vitamin A (retinol) in cooked fish fillets (for both heat treatments) decreased significantly, compared to their content in the raw samples. In contrast vitamin $\mathrm{D}_{3}$ (cholecalciferol) content affects only by steaming, while changes on vitamin E (alpha-tocopherol) was observed solely after frying process. The highest content of monounsaturated fatty acids (MUFA) were observed after steaming, whereas fried samples presented higher values of polyunsaturated fatty acids (PUFA) due to significant increase in linoleic acid (C18:2n6). During steaming did not reduce significant $\mathrm{n} 3$ and $\mathrm{n} 6$ PUFA levels, while frying caused a large reduction of $\mathrm{n} 3$ PUFAs. The ratio of $\mathrm{n} 3 / \mathrm{n} 6$ was markedly lower in fried samples than in raw and steamed mackerel. In conclusion the Black Sea Horse Mackerel is a good source of vitamin $\mathrm{D}_{3}$, vitamin $\mathrm{E}$ and $\mathrm{n} 3$ PUFAs. After steaming and frying process there were minimum losses in the contents of cholecalciferol and alpha-tocopherol, while retinol was reduced nearly a half. The process of frying affects most significantly three fatty acids groups, whereas after steaming was observed little influence on fatty acids profile.
\end{abstract}

Keywords: Trahurus mediterraneus, steaming, frying, vitamins, fatty acids, human health

\section{Introduction}

The Black Sea appears to be one of the important fish basins influencing greatly the economy of all Black Sea countries. The small pelagic species Horse mackerel (Trachurus mediteraneus, Aleev 59), which inhabits the western and north-western parts of the Black Sea [1], is of key importance for Bulgarian fisheries for economic and social reasons (number of fishermen involved) and as livelihood support for population. This carnivore species represents about $50 \%$ of the Bulgarian summer pelagic catches, and a considerable percentage of the Black Sea total catches and plays an important role to provide essential nutrients for the population.
Marine fish, especially carnivores, are characterized by low levels of omega- 6 (n6) fatty acids (linoleic acid LA, C18:2 n6) and high levels of omega-3 (n3) PUFAs (eicosapentaenoic acid, EPA C20:5n3; docosahexaenoic acid, DHA C22:6n3) in particular, which are essential for the human health [2]. Fat soluble vitamins are essential components of fish lipids and are exclusively provided by the diet. Vitamins A and E act as natural antioxidants in the living organisms. All-trans-retinol is very important for the visual system in humans; alpha-tocopherol (alpha-TP) is significant for the normal reproduction and muscle development and cholecalciferol promotes and enhances the absorption and metabolism of calcium and phosphorus. It is well- 
known that some fish species contain high quantities of these vitamins. According to the recommendations of the World Health Organization (WHO) and the Food and Agricultural Organization (FAO) it is advisable to consume annually at least 15-20 kg fish per capita [3]. In Bulgaria the consumption of fish is very low (4.5 $\mathrm{kg}$ annual per capita per year) compared with the average European levels (23 kg annual per capita per year) [4]. Meanwhile, in Western society and Bulgaria, consumption of raw fish is rare, therefore information about FA and fat soluble vitamins content in raw fish tissue may have limited application for nutrition quality assessment. Temperature treatment of fish tissue enhances its taste, inactivates pathogenic microorganisms and increases its shelf life, and yet influences the amounts of fat soluble vitamins and essential fatty acids. Moreover the PUFA, such as EPA and DHA and fat soluble vitamins are considered to be especially susceptible to oxidation during heating process (steaming, boiling, grilling, baking or frying). However information about FA composition and fat soluble vitamins content of raw and cooked (steamed and fried) Black Sea horse mackerel is lacking. The aim of this study was to evaluate FA profile and fat soluble vitamins content and the effect of the cooking methods (steaming and frying) on Black Sea horse mackerel edible tissues.

\section{Experimental}

\subsection{Sampling of fish species}

Fresh Black Sea horse mackerel were purchased from Varna local fish market during summer 2011. The samples were immediately frozen at $-20{ }^{\circ} \mathrm{C}$ and whole stored in a fridge prior to analysis. Biometrical characteristics were determined. One hundred gram sample sizes (whole fishes) were taken for each cooking method. The raw and cooked fish specimens were filleted with skin whereby edible tissue was separated. The fillets of each group were homogenized at $800 \mathrm{rpm}$ for 3 minutes, using Moulinex blender and then analyzed in wet state $(6$ parallel samples).

\subsection{Heat- treatment}

Common ways of heat-treatment were used:
- Steaming - in a steamer above a glass pot of boiling water $(500 \mathrm{~mL})$ and cooked for 10 minutes at $90^{\circ} \mathrm{C}$. Steamed fillets were placed on absorbent papers ( $1 \mathrm{~min}$ of each side) and then processed as described above;

- Frying - in sunflower oil at $180{ }^{\circ} \mathrm{C}$ during $10 \mathrm{~min}$ (5 min for each side). Sunflower oil was used because it is the most common cooking oil in Bulgaria.

Steamed and fried samples were weighed to obtain the weight changes after cooking.

\subsection{Moisture analysis}

Test portions of homogenized fish tissue $(2.000 \pm 0.005 \mathrm{~g})$ were dried at $105 \pm 2^{\circ} \mathrm{C}$ in an air oven to constant weight for 16-18 hours (AOAC 950.46) [5]. All samples were cooled in desiccator and weighed. The moisture $(\%)$ was calculated as weight loss.

\subsection{Lipid extraction}

The raw and cooked edible fish tissue was extracted by the method of Blight and Dyer [6] using chloroform/methanol/water in a ratio 2:2:1. After phase separation, the chloroform extracts were evaporated until dryness. The total lipid content was determined gravimetrically for each group in triplicate. The results were expressed as g per $100 \mathrm{~g}$ wet weigh $\left(\mathrm{g} \cdot 100 \mathrm{~g}^{-1} \mathrm{ww}\right)$.

\subsection{Fatty acids analysis}

Fatty acid compositions of total lipids on edible fish tissue were determined by GC of the corresponding methyl esters. The residual lipid fraction was methylated by base-catalyzed transmethylation using $2 \mathrm{M}$ methanolic potassium hydroxide and n-hexane according to BDS EN 5509:2000 [7]. After 10 minutes centrifugation (3500 rps), the hexane layer was taken for GC analyses. Gas chromatography was performed by a model FOCUS GC equipped with Polaris Q MS detector (Thermo Scientific, USA). TR-5 MS capillary column used (Thermo Scientific, USA). The sample volume was $1 \mu \mathrm{L}$. The three parallel analyses were made from each methanolysed sample. Peaks were identified according to Retention Time (RT) based on available FAME mix standard (SUPELCO F.A.M.E. Mix $\mathrm{C}_{4}-\mathrm{C}_{24: 1}$ ) and mass spectra (ratio $\mathrm{m} / \mathrm{z}$ ). FAMEs was identified and 
quantified by comparison with the RT and peak areas of SUPELCO standards. Three replicate GC analyses were performed. The values of FA were expressed as percentage of total FA mass as a mean value and \pm standard deviation (SD) according to BDS EN 5508:2000 [8]. All of the chemicals used in the experiments were with analytical and GC grade (Sharlau, Sharlab Sourcing Group, Spain).

\subsection{Extraction of fat soluble vitamins and HPLC analysis}

The sample preparation was performed using the method of Dobreva et al [9]. An aliquot of the homogenized sample $(1.000 \pm 0.005 \mathrm{~g})$ was weighed into a glass tube with a screw cap and $1 \%$ of methanolic L-ascorbic acid and $1 \mathrm{M}$ methanolic potassium hydroxide were added. Six parallel samples of edible fish tissue were prepared and subjected to saponification at $80{ }^{\circ} \mathrm{C}$ for $20 \mathrm{~min}$. The components of interest were extracted with n-hexane and the extract was evaporated under nitrogen flow. The dry residue was dissolved in methanol and injected $(20 \mu \mathrm{L})$ into the liquid chromatography system.

Three fat soluble vitamins were analyzed simultaneously using HPLC/UV/FL system (Thermo Scientific Spectra SYSTEM) equipped with analytical column Synergi $4 \mu$ Hydro-RP 80A pore 250x4,6 mm. All-trans retinol and cholecalciferol were detected by UV, alpha-TP by fluorescence detection. The mobile phase composition was 97:3 = $\mathrm{MeOH}: \mathrm{H}_{2} \mathrm{O}$, and the flow rate was $1 \mathrm{~mL} / \mathrm{min}$. The qualitative analysis was performed by comparing the retention times of pure substances: at $\lambda_{\max }=325 \mathrm{~nm}$ for retinol; $\lambda_{\max }=265 \mathrm{~nm}$ for cholecalciferol and alpha-TP fluorescence at $\lambda_{\mathrm{ex}}=288 \mathrm{~nm}$ and $\lambda_{\mathrm{em}}=$ $332 \mathrm{~nm}$. The quantitation was done by the method of external calibration comparing the chromatographic peak areas of the corresponding standards (Retinol solution, Fluka; DL-alpha Tocopherol, Supelco; Cholecalciferol, Supelco). The results are expressed as $\mu \mathrm{g}$ per $100 \mathrm{~g}$ wet weight $\left(\mu \mathrm{g} \cdot 100 \mathrm{~g}^{-1} \mathrm{ww}\right)$.

\subsection{Statistical analysis}

The obtained data were analyzed using Graph Pad Prism 5 software. Column statistic was used for calculation of means and standard deviations and results are presented as average \pm SD. To estimate the differences between three groups - raw, steamed and fried samples was applied two-way ANOVA statistical analysis. Thus the comparison was made to moisture, total lipids, fat soluble vitamins and individual fatty acids and fatty acid groups. The differences were considered significant at $\mathrm{p}<0.05$.

\section{Results and Discussions}

\subsection{Moisture content}

The raw samples of horse mackerel fillets showed maximum moisture content $(78.5 \%)$. During the process of fraying the most significant decrease in moisture, compared to raw tissue, was detected $16.24 \%(\mathrm{p}<0.001)$, while steaming affected less this parameter $-11.86 \%$ (table 1 ). These results are consistent with Sikorski and Kolakowska for trout and Baltic sprat, and possibly due to the fact that fish food experienced water loss in their tissues during the cooking process [10]. Kocatepe et al presented the most significant reduced in moisture content of fried black sea anchovy compared to raw sample [11]. Generally, the moisture content of fish samples seemed to be inversely related to the total lipid content and obtained results in this study confirm this statement.

Table 1 Moisture (\%) and total lipids (g 100g- ${ }^{1} \mathrm{ww}$ ) content in raw, steamed and fried Black Sea horse mackerel (mean \pm SD)

\begin{tabular}{lccc}
\hline Specification & \multicolumn{3}{c}{ H. mackerel } \\
\cline { 2 - 4 } & raw & steamed & fried \\
\hline Moisture & $76.87 \pm 1.50$ & $67.75 \pm 1.22$ & $65.40 \pm 1.25$ \\
Total lipids & $1.20 \pm 0.20$ & $0.95 \pm 0.17^{+++}$ & $3.60 \pm 0.30^{* * *}$ \\
\hline $\begin{array}{l}\text { SD - standard deviation, } \\
\text { fried; }+++\mathrm{p}<0.001 \text { and }++\mathrm{p}<0.005 \text { steamed vs fried }\end{array}$
\end{tabular}

\subsection{Total lipid content}

The total lipid (TL) content in raw horse mackerel was $1.2 \mathrm{~g} 100^{-1} \mathrm{~g}$ wet weight (w.w.). This is typical for horse mackerel which generally has lowest lipid content (1-3 g $\left.100^{-1} \mathrm{~g} \mathrm{ww}\right)$ in summer (June) season [12]. Merdzhanova et al found the similar low TL value for carnivorous Black Sea

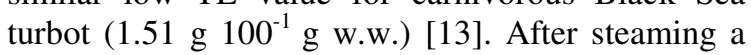
significant $(\mathrm{p}<0.001)$ decrease in $\mathrm{TL}$ content was 
observed $(21 \%)$, whereas frying resulted in a threefold increase of TL amounts $(\mathrm{p}<0.001$, table 1$)$.

Measurements such as total extractable lipids are difficult to compare between studies as differences in lipid content can be caused by diet, season, heat treatment, portion size and heatable surface area $[10$, 11]. In the present study, it was observed that during the lipid extraction process, lipids were more effectively extracted from cooked fish samples rather than raw fish samples. Larsen et al supposed that this may have been due to bound lipids being released as free lipids during the cooking process making them easier to extract [14]. This difference could also be due to mechanical factors, whereby the cooked fish had much softer tissue that was more easily homogenised and therefore more lipids were able to be extracted. The obtained results are consistent with those quoted by other authors, who observed loss of fat due to spreading during steaming in Rainbow trout $[15,16]$. Kocatepe et al presented similar changes for TL of fried Black Sea anchovy, which increased more than twice compared to raw sample [11]. Sionen et al found that the uptake of frying fats into fried fish samples was inversely related to TL content of raw fish, with cod (TL $<1 \mathrm{~g} 100^{-1} \mathrm{~g}$ w.w.) having greater total extractable lipid content than salmon after frying [17].

\subsection{Fatty acid composition}

Twenty-eight fatty acids (from C12:0 to C 24:1) were identified and compared among the different species. There was a wide variation and significant differences $(\mathrm{p}<0.05)$ among the FA profiles after steaming and frying in terms of total and individual saturated and unsaturated FAs. The FA pattern in raw horse mackerel followed the order: SFA $>$ PUFA $>$ MUFA. Statistically, compared to the raw mackerel, steamed samples showed significant increase in the values of total PUFA and MUFA $(p<0.001)$, whereas the SFA amounts decreased slightly $(\mathrm{p}<0.05)$ and FA pattern has changed in the following way: SFA $\approx$ PUFA $>$ MUFA. Frying process affected most significant all FA groups as followed: PUFA $>$ SFA $>$ MUFA. Gladishev et al. reported increased PUFA levels after heat treatment in four fish species and suggested that this may be due to the higher degree of hydrolysis of fish tissue lipids [15]. The comparison of FA profiles (FA \% of total FA) of raw, steamed and fried horse mackerel are shown in table 2. As a result frying leads to significant changes in the levels of the individual fatty acids within the all FA groups.

\subsubsection{Saturated fatty acid}

Fatty acids respond differently to heat treatments. Generally, SFA are fairly heat stable in temperatures encountered during common cooking methods. Steamed mackerel shows increase of FAs levels especially, myristic C14:0 and stearic acid C18:0 $(\mathrm{p}<0.001)$, whereas the levels of palmitic acid C16:0 was significantly reduced $(\mathrm{p}<0.001)$.

A similar trend was observed in fried samples whereas C16:0, C14:0 and C18:0 SFA levels were reduced significant compared to raw and steamed samples. These changes reflect the overall reduction of SFAs in both heat treatment mackerel (especially in fried samples, table 2).

\subsubsection{Monounsaturated fatty acid}

In raw horse mackerel MUFA were the lowest FA group (26.13\% of total FA). This trend was also apparent in the cooked samples. In the raw mackerel MUFA was presented in the highest amounts of palmitoleic acid $\mathrm{C} 16: 1 \mathrm{n} 7$, followed by oleic acid C18:1 n9. In this study the levels of C18:1 n9 increased significantly $(\mathrm{p}<0.001)$ after steaming and frying, whereas C16:1 n7 presented the opposite trends and decreased significant especially in fried samples $(p<0.001)$. Possible explanation for the increase of C18:1n9 levels in fried samples compared to raw is the high level of this FA in used sunflower oil [18]. The increase of C18:1 n9 levels after steaming contributed to higher extent to the elevation of total MUFA content. Larsen et al., reported insignificant effect of steaming on King Salmon MUFA contents, while Su and Babb found significant changes in MUFA levels in steamed scallops [14,19]. There are several possible reasons for discrepancies and differences among the reported results, but one of the most important is the lack of standardized times and temperatures for any cooking method.

On the other hand, the observed results show that the steaming determines loss of TL and different FAs undergo different changes. 
Table 2 Comparison of FA profiles (\% of total fatty acids) in edible tissue of raw, steamed and fried horse mackerel (mean $\pm \mathrm{SD})$

\begin{tabular}{|c|c|c|c|}
\hline \multirow[t]{2}{*}{ Fatty Acid } & \multicolumn{3}{|c|}{ Horse mackerel } \\
\hline & raw & steamed & fried \\
\hline \multicolumn{4}{|c|}{ Saturated fatty acids } \\
\hline C 12:0 & $0.46 \pm 0.07$ & $0.40 \pm 0.05$ & $0.20 \pm 0.02$ \\
\hline C $14: 0$ & $2.10 \pm 0.38$ & $2.35 \pm 0.25$ & $1.60 \pm 0.54$ \\
\hline C $16: 0$ & $29.40 \pm 1.08$ & $27.18 \pm 0.87$ & $24.30 \pm 1.04$ \\
\hline C 17:0 & $0.60 \pm 0.10$ & $0.60 \pm 0.06$ & $0.30 \pm 0.04$ \\
\hline C $18: 0$ & $3.80 \pm 0.25$ & $4.60 \pm 0.45$ & $3.10 \pm 0.80$ \\
\hline C 20:0 & $0.60 \pm 0.03$ & $0.60 \pm 0.04$ & $0.50 \pm 0.03$ \\
\hline C 21:0 & $0.30 \pm 0.02$ & $0.16 \pm 0.02$ & $0.20 \pm 0.01$ \\
\hline C 22:0 & $0.55 \pm 0.05$ & $0.56 \pm 0.01$ & $0.50 \pm 0.04$ \\
\hline C 23:0 & $0.25 \pm 0.05$ & $0.20 \pm 0.02$ & $0.18 \pm 0.01$ \\
\hline C 24:0 & $0.85 \pm 0.09$ & $0.76 \pm 0.07$ & $0.50 \pm 0.04$ \\
\hline$\Sigma$ SFA & $39.36 \pm 1.15$ & $\mathbf{3 7 . 5 5} \pm 1.20^{+++}$ & 32.03 $\pm 1.50 * * *$ \\
\hline \multicolumn{4}{|c|}{ Monounsaturated fatty acids } \\
\hline C 14:1 n5 & $0.30 \pm 0.04$ & $0.35 \pm 0.05$ & $0.15 \pm 0.02$ \\
\hline C $16: 1 \mathrm{n} 7$ & $14.30 \pm 0.54$ & $12.10 \pm 0.65^{+++}$ & $5.40 \pm 0.05 * * *$ \\
\hline C $17: 1 \mathrm{n} 8$ & $0.40 \pm 0.03$ & $0.45 \pm 0.05$ & $0.20 \pm 0.01$ \\
\hline C 18:1 n9 & $8.15 \pm 0.37$ & $12.25 \pm 0.58^{+++}$ & $11.80 \pm 0.80 * * *$ \\
\hline C 20:1 n9 & $0.50 \pm 0.05$ & $0.48 \pm 0.06$ & $0.30 \pm 0.04$ \\
\hline C 22:1 n9 & $0.80 \pm 0.04$ & $0.86 \pm 0.04$ & $0.30 \pm 0.01$ \\
\hline C 24:1 n9 & $1.68 \pm 0.23$ & $1.45 \pm 0.15$ & $0.40 \pm 0.01$ \\
\hline$\Sigma$ MUFA & 26.13 \pm 1.05 & $27.94 \pm 1.10^{+++}$ & $\mathbf{1 8 . 5 5} \pm 1.25^{* * *}$ \\
\hline \multicolumn{4}{|c|}{ Polyunsaturated fatty acids } \\
\hline C $18: 3$ n6 & $0.50 \pm 0.03$ & $0.30 \pm 0.05$ & $0.10 \pm 0.01$ \\
\hline C $18: 2$ n6 & $5.15 \pm 0.24$ & $6.50 \pm 0.30$ & $40.31 \pm 2.55^{* * *}$ \\
\hline C $18: 3$ n3 & $0.80 \pm 0.05$ & $0.65 \pm 0.04$ & $0.30 \pm 0.04$ \\
\hline C $20: 5$ n3 & $1.35 \pm 0.10$ & $1.95 \pm 0.40^{+++}$ & $0.50 \pm 0.05 * * *$ \\
\hline C 20:4 n6 & $2.90 \pm 0.35$ & $3.08 \pm 0.60$ & $1.00 \pm 0.10$ \\
\hline C 20:2 n6 & $0.85 \pm 0.08$ & $0.95 \pm 0.10$ & $0.20 \pm 0.03$ \\
\hline C $20: 3 \mathrm{n} 3$ & $1.00 \pm 0.10$ & $1.10 \pm 0.12$ & $0.30 \pm 0.01$ \\
\hline C 20:3 n6 & $1.15 \pm 0.10$ & $0.20 \pm 0.01$ & $0.15 \pm 0.01$ \\
\hline C 22:6 n3 & $21.61 \pm 1.25$ & $22.93 \pm 1.30^{+++}$ & $6.36 \pm 0.08 * * *$ \\
\hline C 22:2 & $0.50 \pm 0.04$ & $0.50 \pm 0.05$ & $0.20 \pm 0.02$ \\
\hline$\Sigma$ PUFA & $\mathbf{3 5 . 0 4} \pm 1.55$ & $\mathbf{3 7 . 3 5} \pm 1.68^{+++}$ & 49.42 $\pm 2.50 * * *$ \\
\hline$\sum \mathrm{n} 3$ & $24.76 \pm 1.05$ & $26.63 \pm 1.10^{+++}$ & $7.46 \pm 0.80 * * *$ \\
\hline$\Sigma \mathrm{n} 6$ & $9.70 \pm 0.80$ & $10.08 \pm 1.05$ & $41.56 \pm 2.20 * * *$ \\
\hline $\mathrm{n} 3 / \mathrm{n} 6$ & $2.55 \pm 0.60$ & $2.64 \pm 0.85$ & $0.20 \pm 0.05^{* * *}$ \\
\hline PUFA/SFA & $0.90 \pm 0.07$ & $0.99 \pm 0.10$ & $1.54 \pm 0.15$ \\
\hline
\end{tabular}

\subsubsection{Polyunsaturated fatty acid}

In this study the PUFA in raw mackerel was dominated by DHA and EPA as the most abundant n3 FAs and LA and C 20:4 arahidonic acid (AA) from n6 FA. The n3 PUFA content of horse mackerel was of particular interest in this study.
Results show that $\mathrm{n} 3 \mathrm{FA}$ value (as \% of total FAs) in raw samples was $24.76 \%$ and was predominately due to the long chain PUFA (LCPUFA) as DHA $(21.61 \%)$ and EPA (1.35\%). In general, in this research EPA levels were found significantly lower than those of DHA in all samples. It is well known that EPA and DHA are highly polyunsaturated and more vulnerable to the oxidation even at ambient temperature compared to LA n-6 and their contents strongly depend on a storage conditions $[10,14,15]$. This study found that steaming process resulted in significant increase in n3 LCPUFA levels, while frying leads to significant reduce on DHA and EPA levels compared to raw samples $(\mathrm{p}<0.001$, as $\%$ of total FA). Changes in EPA and DHA levels observed in this study could be caused by changes in lipid extractability. The opposite trend was observed for n6 PUFA content, which was significantly higher in fried horse mackerel ( $\mathrm{p}<0.001$, as $\%$ of total FA). Zlatanov et al, 2008 presented GC analyses of the sunflower oil used in frying processes and found that LA (56\%) and C18:1 (40\%) were the main FAs [18]. Consistently, fried horse mackerel showed higher concentration of these FAs. The higher proportion of LA from the cooking oil also contributed to the lowest n-3/n-6 PUFA ratio in fried samples.

$\mathrm{Su}$ and $\mathrm{Babb}$ found increase in DHA and decrease of EPA content in steamed scallops. Some discrepancies were found when comparing the obtained results with results involving amounts of EPA and DHA quoted by other authors [19]. About $25 \%$ higher amounts of EPA and DHA, in comparison with boiled humpback salmon raw fillets and trout fillets were observed by Gladyshev et al [15]. Kolakowska et al. suggested that different heat treatment procedures had no substantial influence on the percentage of EPA and DHA in Baltic herring [16]. In other research the same authors reported that heating for $20 \mathrm{~min}$ at $160^{\circ} \mathrm{C}$ could reduce DHA and EPA contents in sprat and mackerel [10].

When presenting the LCPUFA content in absolute amounts (mg $100 \mathrm{~g}^{-1}$ wet weight) is possible to provide more useful and accurate information for observed PUFA changes after heat treatments. In this study was found that $100 \mathrm{~g}$ of raw fillet contained $224.0 \mathrm{mg}$ of EPA+DHA (table 3). Stancheva et al found significant low EPA+DHA amounts: from 13.15 to $55.00 \mathrm{mg} \cdot 100^{-1} \mathrm{~g} \mathrm{w} . \mathrm{w}$. for 
Black Sea sprat and goby [20]. This sum is slightly decreased to $195.0 \mathrm{mg}(13 \%)$ after steaming, while frying leads to reduction with $18.3 \%$ (183.0 $\mathrm{mg}$ ).

Table 3 Long chain PUFA content (g $100 \mathrm{~g}^{-1}$ raw tissue) in raw, steamed and fried horse mackerel $($ mean $\pm \mathrm{SD})$

\begin{tabular}{lccc}
\hline Fatty & \multicolumn{3}{c}{ H. mackerel } \\
\cline { 2 - 4 } & raw & steamed & fried \\
& & & \\
\hline EPA & $0.014 \pm 0.003$ & $0.015 \pm 0.004$ & $0.013 \pm 0.004$ \\
DHA & $0.210 \pm 0.06$ & $0.180 \pm 0.06$ & $0.170 \pm 0.05$ \\
$\Sigma$ n 3 & $0.240 \pm 0.08$ & $0.210 \pm 0.15$ & $0.200 \pm 0.10^{* * *}$ \\
$\Sigma$ n 6 & $0.100 \pm 0.05$ & $0.080 \pm 0.02$ & $1.200 \pm 0.30 * * *$ \\
\hline \multicolumn{5}{l}{$S D$ - standard deviation, *** $p<0.001$} \\
\end{tabular}

Lack of negative influence of cooking procedure on the EPA+DHA content of horse mackerel fillets has high practical importance. According to the International Society for the Study of Fatty Acids and Lipids, the minimum daily consumption of EPA+DHA by healthy persons that reduces the risk of developing cardiovascular diseases is at least 500 mg [21]. This study shows that in order to meet the above norm it is necessary to consume $200 \mathrm{~g}$ portion of horse mackerel, which is a good sources of both n3PUFAs.

The n3/n6 PUFA ratio is known to be of dietetic importance, since it is a key factor for balanced synthesis of eicosanoids in the organism [21,22]. A previous study revealed that $\mathrm{n} 3 / \mathrm{n} 6$ ratio in marine fishes is between 0.7 and 14.4 [23]. The obtained results in this study for raw species (2.55) are in agreement with the above mentioned results. The observed differences in omega PUFA levels after steaming results in a slightly increase of $\mathrm{n} 3 / \mathrm{n} 6$ ratio $(3.5 \%)$, while in fried mackerel was found dramatically decrease - with $92 \%$ (table 2). Gladishev et al., Su and Babb and Larsen et al. reported a significant decrease in $\mathrm{n} 3 / \mathrm{n} 6$ ratio in steamed, boiled and especially fried fish species (over 70\%) and thus support presented results [14, 15,19]. According to the current WHO recommendations, n3/n6 PUFA should not be lower than 0.2 [22,24]. In analysed fish species (before and after heat treatments) this ratio remains significantly above the cut-of value of 0.2 .
Other useful key indicator for evaluation of fish nutritional quality is PUFA/SFA ratio. Values of PUFA/SFA ratio greater than 0.45 are recommended by Department of Health [25]. Simopolous and Etherton reported that several studies found inverse association of the PUFA/SFA ratios with cardiovascular diseases and suggested that replacement of SFA with PUFA in the diet would decrease similar health problems $[2,22]$. In this study PUFA/SFA ratios were between 0.90 and 1.54 for studied fish species (table 2). The most balanced PUFA/SFA ratio was obtained for steamed samples (0.99). We found that steaming increases PUFA/SFA ratio by $10 \%$, whereas for frying samples it was changed with $41.5 \%$ (up to 1.54 ). Presented results reveal that both cooking methods do not induce a reduction of PUFA/SFA ratio below 0.45 .

\subsection{Fat soluble vitamins content}

Alpha-TP and especially all-trans-retinol are known to be unstable when heated in the presence of air. The steaming and grilling affects mainly the content of these vitamins. It is well known that the stability of cholecalciferol strongly depends on the used heating process of cooking. In this study significant differences $(\mathrm{p}<0.05)$ in analyzed vitamins contents between different raw and cooked fish samples were established (table 4).

Table 4 Vitamin contents in raw and steamed fish fillets, $\mu \mathrm{g} 100 \mathrm{~g}^{-1} \mathrm{ww},($ mean $\pm \mathrm{SD})$

\begin{tabular}{|c|c|c|c|}
\hline \multirow{2}{*}{ 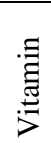 } & \multicolumn{3}{|c|}{ H. mackerel } \\
\hline & raw & steamed & fried \\
\hline $\mathrm{A}$ & $44.9 \pm 2.4$ & $21.9 \pm 0.9^{* * *}$ & $125.9 \pm 14.1^{* *,++}$ \\
\hline $\mathrm{D}_{3}$ & $15.7 \pm 0.8$ & $18.5 \pm 1.4^{*}$ & $20.2 \pm 1.1^{* *,++}$ \\
\hline $\mathrm{E}$ & $2519 \pm 67$ & $4639 \pm 190^{* *}$ & $9776 \pm 159^{* * *,+++}$ \\
\hline
\end{tabular}

Fat soluble vitamins content in raw fish samples correlated with those presented from Erkan et al. and Dobreva et al. [26, 27]. They analyzed retinol and alpha-TP in horse mackerel raw tissue. The vitamin A amount determined by Erkan et al. (141.0 $\mu \mathrm{g} 100$ $\left.\mathrm{g}^{-1} \mathrm{ww}\right)$ is three times higher from ours, while that of Dobreva et al is lower [26, 27]. In the case of vitamin $\mathrm{E}$ amounts - our result is about three times 
higher compared with those by other authors -773.0 $\mu \mathrm{g} \quad 100 \mathrm{~g}^{-1} \quad \mathrm{ww}$ and $642.0 \mu \mathrm{g} \quad 100 \mathrm{~g}^{-1} \mathrm{ww}$, respectively. These differences may be caused by the season of catch - summer is spawning season for horse mackerel fish species. The alpha-TP value in horse mackerel's raw fish tissue $\left(2519 \mu \mathrm{g} 100 \mathrm{~g}^{-}\right.$ $\left.{ }^{1} \mathrm{WW}\right)$ is very close to that in turbot's raw fillets ( 2837 $\left.\mu \mathrm{g} 100 \mathrm{~g}^{-1} \mathrm{ww}\right)$ presented by Stancheva et al. [28].

Horse mackerel is amongst the fishes comprising highest amounts of cholecalciferol. Our data for vitamin $D_{3}$ content in raw fish tissue are in accordance with data given in Whole Food Catalog Database (2011) $\left(8.0 \mu \mathrm{g} 100 \mathrm{~g}^{-1} \mathrm{ww}\right)$ in fishes [29].

The amounts of all-trans retinol, cholecalciferol and alpha-tocopherol were compared with the recommended daily intake (RDI) adopted in Bulgaria [30]. According to that raw analyzed fish edible tissue showed very low percentages for the daily recommended intake of retinol (about $6 \%$ ). For alpha-TP and especially for cholecalciferol the fillets revealed significantly higher percentage almost $17 \%$ and $315 \%$, respectively.

Both cooking processes influenced significantly the amounts of all analyzed vitamins. Retinol content in steamed fish fillets decreased significantly $(\mathrm{p}<0.005)$, when compared to their content in the raw fish samples by about $49.0 \%$, while the amounts of alpha-TP $(\mathrm{p}<0.001)$ and cholecalciferol $(\mathrm{p}<0.05)$ increased by about $45.7 \%$ and $14.8 \%$.

There is a divergence in the published results regarding the effect of different types of cooking on the fat soluble vitamin contents in fish tissue $[26,29]$. Erkan et al. found out losses of about $75 \%$ for retinol and $55 \%$ for alpha-TP in steamed horse mackerel [26].The present results, regarding retinol changes are comparable.

Mattila et al. reported losses below $10 \%$ for cholecalciferol in fish samples undergoing a baking process, while we established slight increases in fish fillets after steaming [31]. In contrast Ersoy and Ozeren reported no significant differences in fat soluble vitamins $\mathrm{A}$ and $\mathrm{E}$ in African catfish edible tissue after various types of cooking - baking, grilling, microwaving and frying [32].

In the case on fried fish fillets, amounts of three fat soluble vitamins are increased significantly. This effect is negligible in the case of cholecalciferol content. Considerable differences for the other two vitamins are probably due to the enriched content of the vegetable oil in which fillets are fried [18].

\section{Conclusion}

Horse mackerel is a good source of n3 PUFAs. A $100 \mathrm{~g}$ portion of fillet delivers between 183 and 224 mg of EPA+DHA sum, depending of the applied method of cooking. This is about $50 \%$ of daily recommended amounts of these FAs. Although frying process reduced $n 3 / n 6$ ratio, the absolute $n 3$ PUFA content is still high and comparable with other seafood. Taking into an account that n3 PUFA deficiency involves mainly LCPUFA; horse mackerel is a valuable source of these FAs. Moreover, due to lower fat content, proper $n 3 / n 6$ and PUFA/SFA ratios, it can be alternative to products such as pork or chicken meats.

The Horse mackerel fish fillets provide considerable amounts of vitamin $\mathrm{D}_{3}$, per serving almost threefold the daily average intake.

The process of fish steaming affects solely the retinol content. On the contrary alpha-TP increased almost twice. In contrast with described changes, fried samples showed increased amounts of the three vitamins compared with raw and steamed fillets.

\section{References}

*E-mail adrress : a.merdzhanova@gmail.com

[1] Chapter 9. The State of marine living resources (V. Shlyakhov \& G. Daskalov) http://www. Blacksea-commission.org/_publ-SOE 2009CH9.asp.

[2] K. Etherton, D. Taylor, S. Yu-Poth, P. Huth, K. Moriarty and V. Fishell, Am J Clin Nutr 71, 1795-1885 (2000).

[3] FAO /WHO (2005) http://www.fao.org /docrep/003 /X8576M/x8576m05.htm

[4] *** Health of the Nation Report. Doclad zdrave na nacia 2009.pdf http://ncphp.government.bg

[5] *** AOAC 950.46 (2001)

[6] E. Bligh, and W. Dyer, Canadian Journal of Biochemistry and Physiology 37, 913-917 (1959).

[7] $* * *$ BDS EN ISO 5509 (2000)

[8] *** BDS EN ISO 5508 (2000) 
[9] D.A. Dobreva, B.Galunska and M. Stancheva,. Scripta Scientifica Medica, Varna Medical University 43, 276-279 (2011)

[10]Z. Sikorski and A. Kolakowska. Chemical and functional properties of food lipids, ACRC Press. London, New York, Washington. 2003

[11]D. Kokatepe, Turan H.G. Taskaya, Y. Kaya, R. Erden and F. Erdogdu. GIDA 36 (2), 71-75 (2011)

[12]M. Yankova, D. Pavlov and V.Raykov, The Annals of the University Dunarea de Jos of Galati, pp 70-77, International Symposium Euro - aliment 2009, 9th - 10th of October 2009, Galati - ROMANIA

[13] A.Merdzhanova, M. Stancheva, L. Makedonski, Ovidius University Annals of Chemistry. 23, 1, 41-47 (2012)

[14]D. Larsen, S.Y Quek and L.Eyres, Food Chem. 119, 785-790 (2010).

[15] M. I. Gladyshev, N.Sushchik, G. Gubanenko., S.Demirchieva, G. Kalachova, Food Chem. 101, 1694-1700 (2007)

[16]A. Kołakowska, Z.Domiszewski and G. Bienkiewicz, Omega 3 fatty acid research. Ed. M.C. Teale. Nova Science Publ. 83-107. (2006)

[17]I. Sioen, Haak L., Raes K., Hermans C., De Henauw S., De Smet S. and Van Camp J Food Chem. 98, 609-617 (2006).

[18] M. Zlatanov, G. Antova, M. Angelova-Romova, B. Damyanova, S. Momchilova and I. Marecov. Hranitelno-vkusova promishlenost 3, 45-47 (2008) (BG)

[19] Q.Su and J. R Babb, Asia Pac J Clin Nutr. 16 (Supp1 1), 407-411 (2007)
[20] M. Stancheva, A. Merdzhanova, D. Dobreva, L. Makedonski, Ovidius University Annals of Chemistry, 21, 1, 23-28 (2010)

[21]***ISSFAL. International Society for the Study of Fatty Acids and Lipids, 2004.

[22] A. Simopoulos and L. Cleland. World Rev Nutr Diet. Basel Karger 92, 1-22 (2003).

[23] R.J. Henderson and Tocher D.R. Progress in lipid research. 26, 281-347 (1987).

[24]***FAO Food and Nutrition Paper 91 www.fao.org/docrep/013/i1953e/i1953e00.pdf), 2010.

[25] *** Department of Health Nutritional aspects of cardiovascular disease: Health and social subsects. HMSO, London (1994)

[26]N. Erkan, A. Selcuk and A. Ozden, Food Analytical Methods 3, 269-275 (2010)

[27]D. A. Dobreva, M.Stancheva, A. Merdzhanova and L. Makedonski, Asian Chemistry Letters, 15, 1 and 2, 91-100 (2011)

[28] M. Stancheva, D. A. Dobreva and B. Galunska, Ovidius University Annals of Chemistry, 23, 1,31-34 (2012)

[29] *** Whole Food Catalog Database [http://wholefoodcatalog.info/food/atlantic_hors e_mackerel (raw)/nutrients/ (2011)

[30]*** Ordinance № 23 / 19.07.2005 on the physiological feeding of population http://bg.wikipedia.org/wiki/Физиологични_но рми_за_хранене\#сіte_note-echo-9

[31]P. Mattila, R. Ronkainen, Lehikoinen, K. Piironen, V. Journal of Food composition and analysis 12, 153-160 (1999).

[32] B. Ersoy and A. Ozeren, Food Chem. 115, 419422 (2009). 